\title{
Global health education in United States anesthesiology residency programs: a survey of resident opportunities and program director attitudes
}

\author{
Gunisha Kaur, Sheida Tabaie, Jasmit Brar, Virginia Tangel and Kane O. Pryor
}

\begin{abstract}
Background: Interest in global health during postgraduate residency training is increasing across medical specialties, and multiple disciplines have categorized global health training opportunities in their arena. No such cataloging exists for anesthesiology residency programs. The aim of this study was to assess and characterize global health opportunities and the attitudes of program directors (PDs) in U.S. anesthesiology residency programs towards this training.

Methods: A cross-sectional 20-question survey on global health opportunities was distributed to 128 ACGME accredited anesthesiology residency program directors via email between October 2015 and January 2016. Descriptive statistics and exploratory inferential analyses were applied. Maximal nonresponse selection bias was estimated.

Results: The overall response rate was $44 \%$. Of those who responded, $61 \%$ reported that their residency program had a global health elective, with a maximal bias estimate of $6.5 \%$. $45 \%$ of program directors with no global health elective reported wanting to offer one. $77 \%$ of electives have articulated educational goals, but there is substantial heterogeneity in curricula offered. Program director attitudes regarding the value of global health programs differed significantly between those with and without existing programs.

Conclusions: The proportion of U.S. anesthesiology residency programs offering global health electives is similar to that in other medical specialties. There is inconsistency in program structure, goals, curriculum, and funding. Attitudes of program directors differ between programs with and without electives, which may reflect bidirectional influence to be investigated further. Further studies are needed to codify curricula, assess effectiveness, and validate methodologies.
\end{abstract}

Keywords: Residency education, Global health training, Anesthesiology education, International electives, Graduate medical education

\section{Background}

Global health is a field dedicated to addressing medical problems that transcend national boundaries. Interest in global health during postgraduate residency training is increasing across medical specialties. Anesthesiology resident physicians have demonstrated their interest in global health work. A recent study of resident physicians showed an overwhelming $91 \%$ of 460 participants indicating their interest in global health opportunities; additionally, $78 \%$ of participants agreed that the availability of a global health outreach residency track would

* Correspondence: gus2004@med.cornell.edu

525 East 68th Street Box 124, New York, NY 10065, USA influence their program ranking during the residency match [1]. Global health electives during residency have been well described for other medical specialties such as internal medicine, pediatrics, general surgery, and obstetrics and gynecology [2]. Information on global health exposure and offerings among anesthesiology training programs has yet to be described.

As resident physicians engage in global health electives with appropriate training, associated benefits include improved medical knowledge and diagnostic skills, increased awareness of social determinants of health, enhanced cultural understanding, exposure to a broad spectrum of illnesses, and greater appreciation of resource utilization [3]. 
However, without appropriate education and preparation, medical work in the developing world may disrupt existing healthcare infrastructure, inappropriately utilize scarce resources, and compromise patient care due to substandard provision of care by trainees [4]. Despite the increase in global health electives and the potential benefits and challenges of these programs, current global health offerings, level of preparation and training provided, and attitudes of program directors towards such education is a virtually unexplored domain in anesthesiology.

The aim of this study was to assess and characterize current global health opportunities and the attitudes of program directors in U.S. anesthesiology residency programs towards this training.

\section{Methods}

\section{Participants}

A cross-sectional survey of the program directors of the 133 anesthesiology residency programs accredited by the Accreditation Council for Graduate Medical Education (ACGME) was conducted. Program directors were identified through the list of programs by specialty published on the public ACGME website. ${ }^{1}$ E-mail addresses were confirmed first directly through program websites, and if unavailable through these websites, by directly contacting the telephone number listed for the program online. Five programs were excluded from the study as a result of failed contact due to non-functional e-mail addresses.

\section{Survey conduct}

Data were collected between October 2015 and January 2016. An initial invitation and two reminders were sent via e-mail over the course of the data collection period. These e-mails provided a link to an anonymous webbased survey hosted by the online survey company SurveyMonkey (Palo Alto, CA). The survey consisted of 20 questions (Additional file 1) designed to evaluate the existence of a global health elective, attitudes towards global health education generally, and, for directors of existing programs, the content and structure of their programs. IP addresses associated with survey response were not collected. Informed consent was received from all participants as part of the survey process, prior to the presentation of any questions.

\section{Statistical analyses}

Because the study design aimed to sample the entire population of interest (i.e. all U.S. program directors), a priori power analysis and estimate of required sample size was not indicated. Descriptive statistics were applied, and Pearson's chi-squared tests performed to assess differences in categorical outcomes. Missing data was handled by listwise deletion for each analysis. All analyses were conducted in Stata IC 13 (StataCorp, College Station, TX).
Because survey nonresponse could not be assumed to be completely independent from the variables measured in the survey (i.e. nonresponses were more likely to represent data missing not at random (MNAR) than data missing completely at random (MCAR)), two assessments of potential nonresponse selection bias were performed. First, an estimate for the maximal estimator bias using the technique derived by Bethlehem [5] (eq. 14) was applied. This method, used to estimate the bias resulting from self-selection and non-response in surveys, provides an upper bound for bias when the standard deviation of response probability is at its maximum possible value (based on population size), and it is assumed that there is maximal relationship between response behavior and the target variable. Second, a 'continuum of resistance' model was applied. The assumptions of this model are that nonrespondents most closely resemble respondents who respond only after substantial time lags or reminders; thus, the absence of a significant difference between early and late responses suggests a low nonresponse bias [6]. Responses were thus partitioned into subsets of 'early' and 'late' responses, and Pearson's chi-squared tests used to assess differences in the prevalence of global health programs. Further, as MNAR nonresponse implies a nonprobability sample, confidence intervals are not presented for descriptive statistics.

Approval for this study was received from the IRB of Weill Cornell Medicine. The conduct of the study and manuscript adhere to the guidelines for reporting of observational studies, as outlined by the STROBE statement [7].

\section{Results}

56 of 128 program directors responded to the study, an overall response rate of $44 \%$. Of those who responded, $61 \%(n=34)$ reported that their residency program had a global health elective, and $45 \%(n=10)$ of program directors with no global health elective reported wanting to offer one. Thus, cumulatively, $79 \%(n=44)$ of programs either presently offer or would like to offer a global health elective. Shown in Table 1, the most cited reasons for not having a global health program were a lack of funding (59\%, $n=13)$, a lack of a global health partner or program through which to offer an elective $(50 \%, n=11)$, and a lack of time within the parameters of training $(36 \%, n=8)$ (Additional file 2).

\section{Characteristics of existing programs}

Table 2 shows the structural characteristics of existing global health electives. A variable number of residents per year were allowed to participate in global health electives, ranging from 1 to 18 , with $12 \%(n=4)$ of programs permitting more than 5 residents per year. $71 \%$ 
Table 1 Survey responses from ACGME residency program directors who do not offer a global health elective

\begin{tabular}{ll}
\hline Sample without global health elective & Total \\
& $N=22$ \\
\hline $\begin{array}{l}\text { Would like residency training to have global health elective, } \\
\text { no. (\%) }\end{array}$ & 10 \\
$\begin{array}{l}\text { Reasons for lack of global health elective } \\
\text { Lack of interest }\end{array}$ & $3(13.6)$ \\
Lack of perceived volume of cases abroad & $0(0)$ \\
Lack of funding & 13 \\
& $(59.1)$ \\
Lack of time within parameters of training & $8(36.4)$ \\
Lack of global health partner/program through which to & 11 \\
offer an elective & (50.0) \\
\hline
\end{tabular}

( $n=24)$ of global health electives offered opportunities for post-graduate year 3 residents to participate, while 94\% $(n=32)$ provided opportunities for residents in post-graduate year 4 . The median elective time was 10 days (range $5-30)$, and $97 \%(n=32)$ of programs did not require residents to use any vacation time to complete the elective.

Seventy-seven percent $(n=26)$ of programs reported that their department had established educational outcome goals for each resident while away on a global health elective. $18 \%(n=6)$ reported having a required research component. There was heterogeneity in the education curricula and training provided to residents. Beyond clinical preparation, while $68 \%$ $(n=23)$ of programs addressed poverty, other biosocially relevant topics were covered less frequently. $41 \%(n=14)$ addressed access to natural resources, 26\% $(n=9)$ addressed discrimination, and 9\% $(n=3)$ addressed gender violence. In $61 \%(n=19)$ of electives, residents were evaluated by intradepartmental attending anesthesiologists, while $19 \%(n=6)$ were evaluated by attending anesthesiologists based in the international location.

Thirty-two program directors responded to a subset of questions on program funding. 38\% $(n=12)$ of program directors reported that funding for their electives was derived from internal department sponsorship, while $16 \%(n=5)$ received funds from nongovernment organizations, and $13 \%(n=4)$ from their home institutions. 33\% $(n=10)$ of programs with electives reported that they offer financial support to residents seeking non-program-sponsored mission trips abroad. A total of 33 unique countries were reported as sites of global health electives throughout Central and South America, Africa, and Asia. The countries in which most global health electives took place were China, the Dominican Republic, Ecuador, Ethiopia, and India.
Table 2 Survey responses from ACGME residency program directors who offer a global health elective

\begin{tabular}{ll}
\hline Sample with global health electives & Total \\
\hline Partners, no. (\%) & $N=34$ \\
Internal department funding or endowment & $N=32$ \\
Institutional funding & $12(37.5)$ \\
Nongovernmental organization funding & $4(12.5)$ \\
Grant funding not from a nongovernmental organization & $5(15.6)$ \\
Residents must find their own funding & $3(9.4)$ \\
Curriculum includes biosocial determinants of health, no. (\%) & $1(3.13)$ \\
Contains content on poverty & $N=34$ \\
Contains content on access to natural resources & $23(67.6)$ \\
Contains content on discrimination & $14(41.2)$ \\
Contains information on gender violence & $9(26.5)$ \\
Goals of global health elective, no. (\%) & $3(8.8)$ \\
Programs with educational outcome goals & $N=34$ \\
Programs with required research component & $26(76.5)$ \\
\hline
\end{tabular}

\section{Attitudes toward Global Health electives}

Table 3 shows an exploratory analysis of the attitudes of program directors toward global health electives. Responses to this subset of questions were received from 31 programs that offer electives, and 19 programs that do not. When questioned about the perceived benefits of global health electives, those with and without current programs had similar levels of agreement on the benefit of providing needed health care to underserved areas of developing countries $(77 \%$ vs $79 \%, P=0.90)$, and on the benefit of personal, professional, and institutional development in the spheres of service-oriented action, humanitarian contribution, and outreach to underprivileged individuals and societies ( $81 \%$ vs $74 \%, P=0.56$ ). In contrast, those with current programs were significantly more likely than those without programs to agree that benefits included advancing education in the field of global anesthesia ( $90 \%$ vs $42 \%, P<0.001$ ), generating effective and engaging programs in the developing world that give residents and faculty the opportunity to become well-rounded, globally conscious physicians ( $74 \%$ vs $42 \%, P=0.02$ ), the opportunity for residents to become leaders in the field of global anesthesia research and contribute to global health literature $(68 \%$ vs $32 \%, P=0.01$ ), and developing cross-institutional collaborations ( $68 \%$ vs $32 \%, P=0.01$ ).

For a subset of questions on the perceived value of global health electives, respondents were able to indicate whether they strongly agreed, somewhat agreed, somewhat disagreed, strongly disagreed, or had no opinion. Those with programs were significantly more likely to say that they strongly or somewhat agreed that exposure 
Table 3 Attitudes of program directors towards global health electives

\begin{tabular}{|c|c|c|c|c|}
\hline & $\begin{array}{l}\text { With program } \\
N=31\end{array}$ & $\begin{array}{l}\text { Without program } \\
N=19\end{array}$ & $\begin{array}{l}\text { Total } \\
N=50\end{array}$ & $\begin{array}{l}\text { Comparisons } \\
P\end{array}$ \\
\hline \multicolumn{5}{|l|}{ Sample characteristics } \\
\hline \multicolumn{5}{|l|}{$\begin{array}{l}\text { Value of global health in anesthesiology residency, no. (\% indicating } \\
\text { strongly or somewhat agree) }\end{array}$} \\
\hline Electives are important in training of anesthesiology residents & $27(87.1)$ & $8(42.1)$ & $35(70.0)$ & $<0.001$ \\
\hline Exposure to global health care is a valuable experience & $29(93.5)$ & $13(68.4)$ & $42(84.0)$ & 0.02 \\
\hline $\begin{array}{l}\text { Exposure to global health care should be required of anesthesiology } \\
\text { residency training }\end{array}$ & $10(32.3)$ & $1(5.3)$ & $11(22.0)$ & 0.03 \\
\hline \multicolumn{5}{|l|}{ Perceived benefits of global health electives, no. (\%) } \\
\hline Advancing education in the field of global anesthesia & $28(90.3)$ & $8(42.1)$ & $36(72.0)$ & $<0.001$ \\
\hline $\begin{array}{l}\text { Generating effective and engaging programs in the developing world } \\
\text { that give my department 's residents and faculty the opportunity to } \\
\text { become well-rounded, globally conscious physicians }\end{array}$ & $23(74.2)$ & $8(42.1)$ & $31(62.0)$ & 0.02 \\
\hline $\begin{array}{l}\text { The opportunity for residents to become leaders in the field of global } \\
\text { anesthesia research and contribute to global health literature }\end{array}$ & $21(67.7)$ & $6(31.6)$ & $27(54.0)$ & 0.01 \\
\hline Developing cross-institutional collaborations & $21(67.7)$ & $6(31.6)$ & $27(54.0)$ & 0.01 \\
\hline $\begin{array}{l}\text { Personal, professional, and institutional development in the spheres of } \\
\text { service-oriented action, humanitarian contribution, and outreach to } \\
\text { underprivileged individuals and societies }\end{array}$ & $25(80.6)$ & $14(73.7)$ & $39(78.0)$ & 0.56 \\
\hline Providing needed health care to underserved area of developing countries & $24(77.4)$ & $15(78.9)$ & $39(78.0)$ & 0.90 \\
\hline
\end{tabular}

to global health care is a valuable experience for anesthesiology residents ( $94 \%$ vs $68 \%, P=0.02$ ), and is important for the training of anesthesiology residents ( $87 \%$ vs $42 \%, P<0.001$ ). Those with programs were also significantly more likely to say that exposure to global health electives should be a required component of residency ( $32 \%$ vs $5 \%, P=0.03)$.

\section{Assessment of bias}

The initial email to program directors was sent on November 10, 2015, with follow-up emails on December 1, 2015 and January 23, 2016. There was no significant difference in global health elective status between early and late respondents when the partition was set at December 1, 2015 (early: $n=17, P=0.69$ ), nor when it was set at January 1, 2016 (early: $n=37, P=0.79$ ). The estimate for the absolute value of maximum bias using the method derived by Bethlehem was 6.5\%.

\section{Discussion}

This study assessed current global health opportunities in anesthesiology residency programs by a survey of ACGME accredited anesthesiology residency program directors (PDs). Our survey reports that $61 \%$ of responding programs have global health electives. The calculated maximum bias in this estimate was $6.5 \%$, supporting the generalizability of our results. This proportion is on par with residency global health opportunities in other medical specialties, where $71 \%$ of emergency medicine [8], $61 \%$ of orthopedic surgery [9], 57\% of internal medicine
[10], $52 \%$ of pediatric [11], 74\% of family medicine [12], and $33 \%$ of general surgery programs [13], offer global health electives. Our results show that a majority of responding anesthesiology residency PDs, even those that do not offer electives, agree that global health training is important and that exposure to international healthcare efforts in underserved regions is valuable. Of the respondents without global health opportunities, almost half were interested in initiating such electives. Beyond our primary aim, our exploratory analysis of attitudes towards global health electives revealed significant differences between those with existing programs and those without. While no causation can be inferred, one possibility is that this reflects that PD attitudes drive the establishment of a global health elective, another is that the existence of global health electives influences the attitudes of PDs, and a third is that these globally oriented PDs self-selected into culturally similar employment positions that match their values and are primed to invest in resident education.

With appropriate preparation, global health experiences for post-graduates have the potential to meet each of the six core competencies of the ACGME [14, 15]. Our study demonstrated that while $77 \%$ of responding programs with electives had established educational goals, training was neither comprehensive nor systematic. For example, beyond clinical preparation some programs provided curricula based on relevant biosocial determinants of health, as identified by the United $\mathrm{Na}$ tions $[16,17]$ (e.g. poverty, gender violence, and access 
to natural resources), while others provided little foundational understanding in these arenas. Additionally, while the importance of sustained participation on the ground has been well documented [18], anesthesiology residents participated in electives for a median of just 10 days. Research was found to be only a minor component of the surveyed initiatives at $18 \%(n=6)$, similar to general surgery $(11 \%)$ and emergency medicine programs (26\%); this is not surprising, as elective-based programs are twice as prevalent as research-based programs among offerings in internal medicine, pediatrics, obstetrics and gynecology, family medicine, and psychiatry. Unlike other core areas of anesthesiology training, there exists no guiding academic authority on global health education and research, and no central, reliable source of educational materials. These factors may lead to programs teaching global health inconsistently, without the input of experts, resulting in an incomplete education of residents at best, and harmful or irresponsible medical practice at worst. Without appropriate education, visiting trainees may fail to deliver care that meets standards, disrupt the practice of local healthcare providers or existing healthcare infrastructure [19], inappropriately utilize scarce resources [20], or experience increased personal or professional stress [21] .

There are two important limitations to this study. The first is the susceptibility of the survey methodology to nonresponse selection bias, as attitudes toward global health and the existence of a global health elective could be related to the decision to respond to the survey. We performed analyses using two techniques for estimates of bias (one statistically derived, and the other empirically derived from prior research on response behavior), which taken together suggest that the absolute bias for the estimate of programs was within $6.5 \%$, which would not alter the qualitative conclusions. Web-based surveys are at risk for low response rates [22], although our rate of $44 \%$ was comparable to response rates in similar webbased survey studies on global health conducted by other medical specialties such as general surgery (29\%) [13], obstetrics and gynecology (28\%) [23], and emergency medicine (53\%) [20]. The second important limitation is that the survey instrument we used, although informed by prior research, is novel and has not undergone validation analysis. The questions and results are represented as being clustered into multiple constructs, but it must be noted that these constructs were conceptually derived, and have not been assessed in exploratory or confirmatory factor analysis.

\section{Conclusions}

The data from this study demonstrate that global health opportunities in anesthesiology, though similar to offerings in other medical specialties, is not readily accessible, comprehensive, or consistent. There is significant variation in program structure, goals, curriculum, and funding. Attitudes of PDs differ between programs with and without electives, which may reflect bidirectional influence to be investigated further. Future investigations may aim to identify milestones in global health literacy and incorporate standardized competencies in systematic education, with the guidance of experts in the field. The data from this study are critically relevant to educators who are designing global health programs for trainees. They highlight opportunities to improve education in the field of global anesthesiology and describe the critical starting points.

\section{Endnotes}

${ }^{1}$ https://apps.acgme.org/ads/Public/Reports/Report/1. Last accessed October 12, 2016

\section{Additional files}

Additional file 1: Program Director Questionnaire. (PDF 77 kb)

Additional file 2: Comprehensive survey results. (PDF $122 \mathrm{~kb}$ )

\section{Abbreviations}

ACGME: Accreditation Council for Graduate Medical Education; IRB: Institutional Review Board; MCAR: Missing completely at random; MNAR: Missing not at random; PD: Program Director; STROBE: Strengthening the Reporting of Observational studies in Epidemiology

\section{Acknowledgements}

The authors thank Ms. Michele Steinkamp, RN, Research Nurse Specialist, Department of Anesthesiology, Weill Cornell Medicine, New York, NY, USA and Dr. Hugh C. Hemmings, MD, PhD, FRCA, Professor and Chair of Anesthesiology, Professor of Pharmacology, Department of Anesthesiology, Weill Cornell Medicine, New York, NY, USA

\section{Funding}

The authors report no external funding source for this study.

\section{Availability of data and materials}

The datasets used and/or analyzed during the current study are available from the corresponding author on reasonable request.

\section{Authors' contributions}

GK contributed to conception and design of the work, acquisition of data, drafting and revision of manuscript. ST contributed to design of work, acquisition of data, drafting and revision of manuscript. JB contributed to design of work, acquisition of data, drafting and revision of manuscript. VT contributed to data acquisition, analysis, and interpretation. KOP contributed to conception and design of the work, interpretation of data, and revision of the manuscript. All authors read and approved the final manuscript.

\section{Ethics approval and consent to participate}

Approval for this study was received from the IRB of Weill Cornell Medicine, under protocol number 1508016443, approved on 10/27/2015. Written consent was obtained from all participants prior to initiation of study, as participants had to agree to participation in order to proceed to survey questions.

\section{Consent for publication}

Not applicable.

Competing interests

The authors declare that they have no competing interests. 


\section{Publisher's Note}

Springer Nature remains neutral with regard to jurisdictional claims in published maps and institutional affiliations.

Received: 21 March 2017 Accepted: 2 November 2017

Published online: 16 November 2017

\section{References}

1. McCunn M, Speck RM, Chung I, Atkins JH, Raiten JM, Fleisher LA. Global health outreach during anesthesiology residency in the United States: a survey of interest, barriers to participation, and proposed solutions. J Clin Anesth. 2012;24:38-43.

2. Kerry VB, Walensky RP, Tsai AC, et al. US medical specialty global health training and the global burden of disease. J Glob Health. 2013;3:020406.

3. Drain PK, Primack A, Hunt DD, Fawzi WW, Holmes KK, Gardner P. Global health in medical education: a call for more training and opportunities. Acad Med. 2007;82:226-30.

4. Dowell J, Blacklock C, Liao C, Merrylees N. Boost or burden? Issues posed by short placements in resourcepoor settings. Br J Gen Pract. 2014;64:272-3.

5. Bethlehem J. Selection bias in web surveys. Int Stat Rev. 2010;78:161-88.

6. Groves RM. Nonresponse rates and nonresponse bias in household surveys. Public Opinion Quarterly. 2006:70:646-75.

7. von Elm E, Altman DG, Egger M, et al. The strengthening the reporting of observational studies in epidemiology (STROBE) statement: guidelines for reporting observational studies. Lancet. 2007;370:1453-7.

8. Dey CC, Grabowski JG, Gebreyes K, Hsu E, VanRooyen MJ. Influence of international emergency medicine opportunities on residency program selection. Acad Emerg Med. 2002;9:679-83.

9. Clement RC, Ha YP, Clagett B, Holt GE, Dormans JP. What is the current status of global health activities and opportunities in US orthopaedic residency programs? Clin Orthop Relat Res. 2013;471:3689-98.

10. Kolars JC, Halvorsen AJ, McDonald FS. Internal medicine residency directors perspectives on global health experiences. Am J Med. 2011;124:881-5.

11. Nelson BD, Lee AC, Newby PK, Chamberlin MR, Huang CC. Global health training in pediatric residency programs. Pediatrics. 2008;122:28-33.

12. Hernandez R, Sevilla Martir JF, Van Durme DJ, et al. Global health in family medicine residency programs: a nationwide survey of US residency directors: a CERA study. Fam Med. 2016:48:532-7.

13. Jayaraman SP, Ayzengart AL, Goetz LH, Ozgediz D, Farmer DL. Global health in general surgery residency: a national survey. J Am Coll Surg. 2009;208:426-33.

14. Henry JA, Groen RS, Price RR, et al. The benefits of international rotations to resourcelimited settings for U.S. surgery residents. Surgery. 2013;153:445-54.

15. Gladding S, Zink T, Howard C, Campagna A, Slusher T, John C. International electives at the university of Minnesota global pediatric residency program: opportunities for education in all accreditation Council for Graduate Medical Education competencies. Acad Pediatr. 2012;12:245-50.

16. United Nations. Millennium Development Goals. (2016). http://www.un.org/ millenniumgoals/. Accessed 30 November 2016

17. United Nations. Sustainable development knowledge platform. (2016) https://sustainabledevelopment.un.org/ . Accessed 30 November 2016.

18. Natuzzi ES, Rooney J, Chu K, et al. Surgical issues in global health. In: Markle WH, Fisher MA, RAJ S, editors. Understanding Global Health. 2nd ed. New York: McGrawHill; 2014. ch.14.

19. Jesus JE. Ethical challenges and considerations of shortterm international medical initiatives: an excursion to Ghana as a case study. Ann Emerg Med. 2010;55:17-22

20. Havryliuk T, Bentley S, Hahn S. Global health education in emergency medicine residency programs. J Emerg Med. 2014;46:847-52.

21. Butteris SM, Schubert CJ, Batra M, et al. Global health education in US pediatric residency programs. Pediatrics. 2015;136:458-65.

22. Chen LS, Goodson P. Webbased survey of US health educators: challenges and lessons. Am J Health Behav. 2010;34:3-11.

23. Nathan LM, Banks EH, Conroy EM, et al. Global health training in US obstetrics and gynaecology residency programmes: perspectives of students, residents and program directors. Postgrad Med J. 2015:91:685-91.

\section{Submit your next manuscript to BioMed Central and we will help you at every step:}

- We accept pre-submission inquiries

- Our selector tool helps you to find the most relevant journal

- We provide round the clock customer support

- Convenient online submission

- Thorough peer review

- Inclusion in PubMed and all major indexing services

- Maximum visibility for your research

Submit your manuscript at www.biomedcentral.com/submit
C) Biomed Central 